\title{
Case - Temporary chemical castration in the management of recurrent priapism
}

Yooni Yi

University of Michigan

Cite as: Can Urol Assoc J 2018 Feb. 6; Epub ahead of print. http://dx.doi.org/10.5489/cuaj.4875

\section{Published online February 6, 2018}

$* * *$

\section{Introduction}

Stuttering priapism entails repeated, distinct episodes of persistent penile erection despite interval periods of detumescence. While individual episodes are acutely treated, overall management of the patient with recurrent priapism focuses on prevention of future incidents.

According to AUA Guidelines, systemic therapy may be utilized for prevention of priapism - including hormonal agents, baclofen, digoxin, and terbutaline. Other methods of management include self-injection of sympathomimetic agents and surgical intervention with placement of penile prosthesis ${ }^{1}$. This case report describes long-term utilization of hormonal therapy in the management of stuttering priapism in a young male.

\section{Case report}

A 23-year-old male presented to our emergency department for management of recurrent priapism. Prior to presentation, the patient experienced progressive, recurrent episodes of priapism at least 2-3 times per week requiring aggressive physical activity, irrigations, and/or intracavernosal injections at outside facilities. The presumed etiology of his initial episodes of priapism was trazodone administration at age 18, however the medication had been discontinued at that time without abatement of his priapism. Medical management previously attempted included sertraline and bicalutamide, while surgical procedures included distal shunt and subsequent angioembolization of the left cavernosal artery.

Despite aggressive management, the patient continued to have episodes of priapism and was initiated on self-administered phenylephrine injections. In addition, after a discussion of the risks, benefits, and alternatives, he agreed to initiate leuprolide injections (22.5 mg every 3 months). His total testosterone after initiation of treatment was $0.24 \mathrm{ng} / \mathrm{mL}$, and he no longer experienced episodes of priapism. He denied side effects such as depression, hot flashes, fluid retention or decrease in energy. He also denied changes in his body composition, however his weight did increase from $79.5 \mathrm{~kg}$ at the initiation of leuprolide to $85.5 \mathrm{~kg}$ at his most recent clinic visit. Additionally, he reported adequate libido and sufficient erections for intercourse when desired, with sexual health inventory for men (SHIM) scores persistently greater than 20 out of 25 without use of medications. He did note recurrence of his priapism if the leuprolide injections 
were delayed, but he was successfully maintained on leuprolide for 28 months. Bone scan at the termination of therapy revealed normal bone mineral density. Due to concerns about long term effects of hormonal suppression, he was recently transitioned to finasteride, which he has been taking without recurrence of priapism for over 2 months.

\section{Discussion}

Levine and Guss reported a case of an 18-year-old sickle-cell patient with recurrent priapism. The patient was initiated on a gonadotropin-releasing hormone $(\mathrm{GnRH})$ analogue after reviewing data on hormonal manipulation with diethylstilbestrol in the treatment of recurrent priapism. Leuprolide was chosen based on the ability to manipulate circulating testosterone levels, decreased side effects compared to diethylstilbestrol, convenient dosing, and the ability to titrate the medication. Though sexual function was affected, the patient responded well overall and elected to continue with injections, as the treatment benefits in suppression of priapism outweighed the adverse effects ${ }^{2}$.

Another study utilized the combination of epinephrine self-injection along with leuprolide in a patient who was thought to have recurrent priapism secondary to trazodone administration. After two leuprolide injections the patient was free of priapism recurrence at 4 month follow up, and both libido and sexual function were maintained ${ }^{3}$.

Similar to the second of these reports, our patient reported intact libido and sexual function in spite of castrate levels of testosterone and a consequent suppression of his priapism. Regarding the persistence of priapism following discontinuation of the original inciting agent, trazodone, it has been hypothesized that this may be due to irreversible fibrotic changes in penile smooth muscle which persist following the withdrawal of trazodone ${ }^{3}$.

Though the two studies described utilized GnRH analogues, there are many other treatment modalities being investigated including ketoconazole, finasteride, anti-androgens, PDE5 inhibitors, pseudoephedrine, terbutaline, and digoxin ${ }^{4}$. Since the goal of treatment for stuttering priapism is prevention, the approach to treatment in the patient should focus on tolerance and efficacy of the medication, along with a convenient dosing regimen to maximize compliance. In the case of this patient, though leuprolide was very well tolerated for an extended period of time, the choice was eventually made to transition to finasteride due to concerns about long term effects of hormonal manipulation. Finasteride, a $5 \alpha$-reductase inhibitor, has been described as an effective prophylactic therapy for recurrent priapism, though the mechanism by which it acts in this context is unclear ${ }^{5}$. At the time of this report, the patient's priapism remains suppressed after several months of finasteride therapy in spite of discontinuation of leuprolide.

Stuttering priapism remains a difficult case for the urologist to manage as there are no clear algorithms and robust research on treatment modalities is lacking. We proposed a possible algorithm of management based on our experience. Our patient attempted a number of modalities prior to initiating leuprolide in conjunction with self-administered phenylephrine injections as needed in the management of his priapism. This ultimately provided excellent relief 
with minimal side effects for over two years, but the ability to maintain this regimen on a longerterm basis may be limited by concerns about adverse effects. 


\section{References}

1. Drogo K. Montague, MD, Co-Chairman; Jonathan Jarow, MD, Co-Chairman; Gregory A. Broderick, MD; Roger R. Dmochowski, MD; Jeremy PW Heaton, MD; Tom F. Lue, MD; Ajay Nehra, MD; Ira D. Sharlip, MD. Guideline on the Management of Priapism. 2003. Accessed 10.24.2016. https://www.auanet.org/education/guidelines/priapism.cfm.

2. Laurence A. Levine, Stephen P. Guss. Gonadotropin-Releasing Hormone Analogues in the Treatment of Sickle Cell Anemia-Associated Priapism. J Urol 1993; 150: 475-77.

3. Jeffrey Steinberg, Robert C. Eyre. Management of Recurrent Priapism with Epinephrine SelfInjection and Gonadotropin-Releasing Hormone Analogue. J Urol 1995; 153: 152-53.

4. Michael P. Hoeh, Laurence A. Levine. Management of Recurrent Ischemic Priapism 2014: A Complex Condition with Devastating Consequences. Sex Med Rev 2015; 3:24 - 35.

5. Ubirajara Barroso Jr., Thamy C.S. Marques, Hugo F.F. Novaes. Finasteride for recurrent priapism in adolescents: a report on 5 cases. Int Braz J Urol 2012; 38: 682-86 
Fig. 1. Proposal for algorithm of management of stuttering priapism.

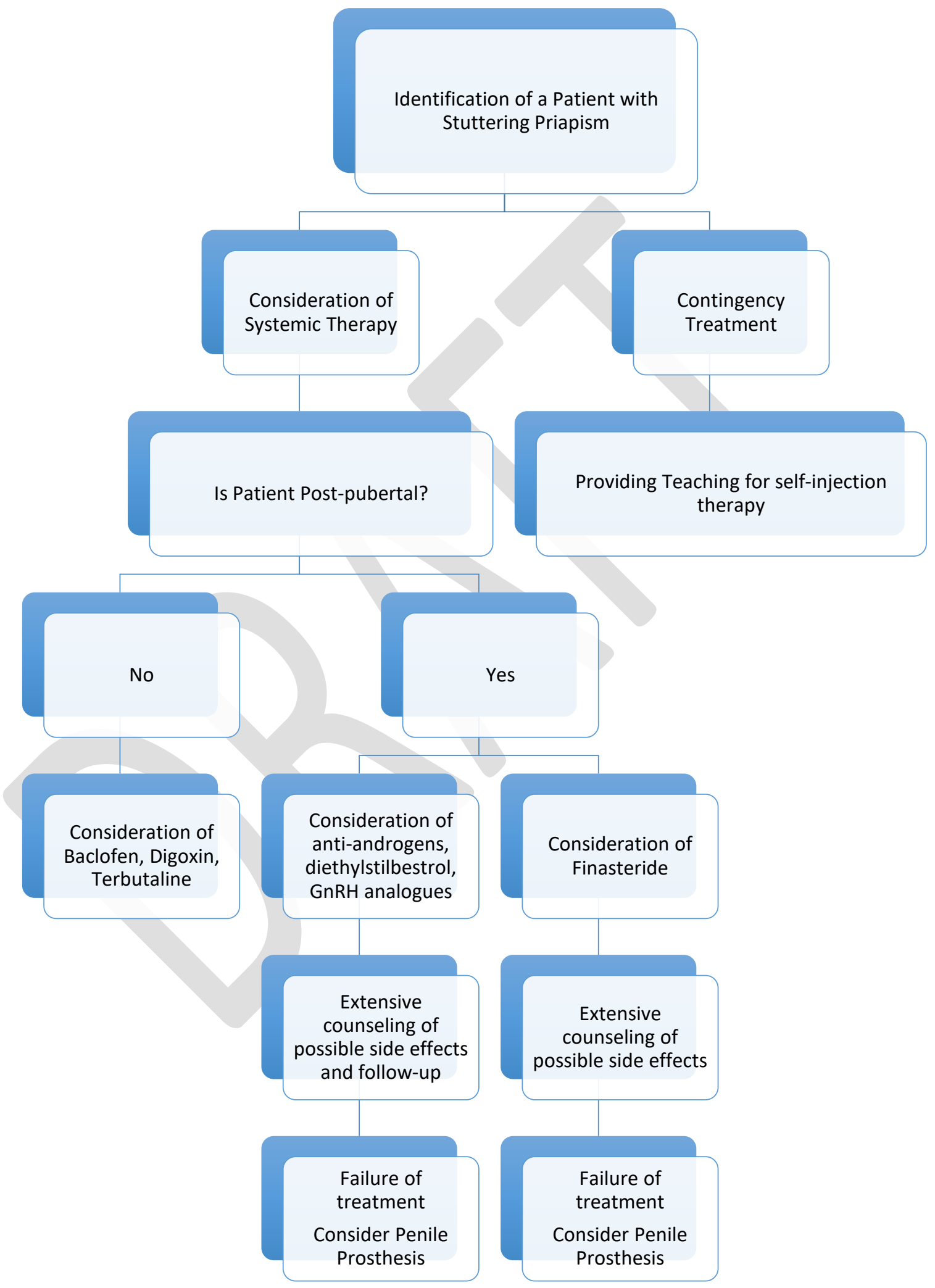

